\title{
Association between tumor necrosis factor alpha rs1800629 polymorphism and risk of osteoarthritis in a Chinese population
}

\author{
Jie Chen, Yu Wu, Jiannong Yu and Jinming Shen \\ Department of Orthopaedics, Zhejiang Provincial Hospital of Traditional Chinese Medicine, Hangzhou, Zhejiang, China
}

\begin{abstract}
Osteoarthritis $(\mathrm{OA})$ is the most common degenerative disease affecting articular cartilage. Some studies indicate that tumor necrosis factor alpha (TNF- $\alpha$ ) gene rs1800629 polymorphism was associated with OA risk among Caucasian populations. To examine the role of this candidate gene in Asian populations, we conducted a hospital-based case-control study involving 257 knee OA patients and 305 controls in a Chinese population. Genotyping was performed using a custom-by-design 48-Plex single nucleotide polymorphism (SNP) Scan ${ }^{\mathrm{TM}}$ kit. Our study indicated that the AA genotype of TNF- $\alpha$ rs 1800629 polymorphism was associated with increased risk of OA. Subsequently, we conducted a meta-analysis and found that rs 1800629 polymorphism increased the risk of $\mathrm{OA}$ in the recessive and homozygous models. Stratification analysis of ethnicity also obtained a significant association among Asian populations. In conclusion, TNF- $\alpha$ rs 1800629 polymorphism confers susceptibility to OA, especially among Asians. Larger studies with more diverse ethnic populations are needed to confirm these results.
\end{abstract}

Key words: TNF- $\alpha$; Osteoarthritis; Polymorphism; Meta-analysis

\section{Introduction}

Osteoarthritis $(\mathrm{OA})$ is characterized by loss of joint cartilage and loss of function primarily in the knees, affecting $9.6 \%$ of men and $18 \%$ of women over 60 years of age (1). This disease could contribute to functional decline in quality of life with heavy health care and society costs (2). Risk factors can be divided into person-level factors, such as age, sex, obesity, genetics, race/ethnicity, and diet, and jointlevel factors including injury, malalignment, and abnormal loading of the joints (3). Twin and family aggregation studies have demonstrated that $\mathrm{OA}$ and its endophenotypes are largely genetically determined, but the underlying genetic variants are mostly unknown (4-6).

Tumor necrosis factor alpha (TNF- $\alpha$ ) is a proinflammatory cytokine, which plays an important role in the pathogenesis of OA (7). A study conducted by Chen et al. demonstrated that interleukin-1 $\beta$ (IL-1 $\beta)$ and TNF- $\alpha$ increased stiffness and impaired contractile function of articular chondrocytes (8). Circulating levels of interleukin-6 (IL-6) and TNF- $\alpha$ were associated with knee OA in older adults (9). In vitro, pro-inflammatory IL-1 $\beta$ and/or TNF- $\alpha$ up-regulate matrix metalloproteases- 1 and -3 mRNA in chondrocyte subpopulations potentially pathogenic in OA (10). In addition, mRNA expression of TNF- $\alpha$ in knee OA patients was 1.56 times greater than in healthy controls. Based on these observations, TNF- $\alpha$ may provide insight into the etiology of OA.

TNF- $\alpha$ is located in the chromosome $6: 31,575,567-$ $31,578,336$. The rs 1800629 polymorphism in the TNF- $\alpha$ gene is also known as the TNF-308 single nucleotide polymorphism (SNP). Occasionally the rs1800629(A) allele is referred to as 308.2 or TNF2, with the more common $G$ allele being 308.1 or TNF1. The A allele is associated with higher levels of TNF expression (Ensemble database). Recently, many studies assessed the association between TNF- $\alpha$ rs 1800629 polymorphism and OA risk, but conflicting results were yielded (11-20). Some studies observed positive findings between rs1800629 polymorphism and OA risk, but others did not. Therefore, to validate whether this single nucleotide polymorphism confers susceptibility to OA in a Chinese population, we conducted this hospital-based casecontrol study.

\section{Material and Methods}

\section{Study subjects}

A total of 257 patients diagnosed with knee OA and 305 age-matched unrelated healthy controls were recruited in this study. The diagnosis of knee OA followed the criteria 
of the American College of Rheumatology, and radiographic findings of $\mathrm{OA}$ were categorized into Kellgren-Lawrence $(\mathrm{KL})$ grades 1, 2, 3 or 4 (21). Patients with other diseases such as gout, rheumatoid arthritis, systemic lupus erythematosus, psoriasis, and developmental dysplasia were excluded from this study. Control subjects were selected among people without personal and family history of OA.

We obtained approval for the study protocol from the Ethics Committee of Zhejiang Provincial Hospital of Traditional Chinese Medicine (China). This study was conducted in line with the Declaration of Helsinki. All patients provided written informed consent prior to their participation.

\section{DNA extraction and genotyping}

Two milliliters of peripheral blood from each patient was collected using vacutainers and transferred to test tubes containing ethylenediaminetetraacetic acid (EDTA). DNA was extracted from blood samples using the QIAamp DNA Blood Mini Kit (Qiagen, Germany) and stored at $-20^{\circ} \mathrm{C}$. SNP genotyping was performed using a custom-by-design 48-Plex SNP Scan ${ }^{\mathrm{TM}}$ kit (Genesky Biotechnologies Inc., China).

\section{Statistical analysis}

Differences in demographic characteristics, variables, and genotypes of the TNF- $\alpha$ rs1800629 polymorphism were evaluated using a chi-squared test. The association between TNF- $\alpha$ rs1800629 polymorphism and risk of OA was estimated by computing odds ratios (ORs) and 95\% confidence intervals (Cls) using logistic regression analyses. The Hardy-Weinberg equilibrium (HWE) principle was tested by a goodness-of-fit chi-squared test, to compare the observed and expected genotype frequencies among controls. Statistical analyses were performed using the SAS software package (version 9.1.3; SAS Institute, USA). To fully investigate the association of TNF- $\alpha$ rs1800629 polymorphism with $\mathrm{OA}$, we also conducted a meta-analysis, which was performed using the Stata 11.0 software (StataCorp, USA).

\section{Results}

\section{Characteristics of the study population}

Patient demographics and risk factors in OA are summarized in Table 1. Subjects were adequately matched for age and $\operatorname{sex}(P=0.854$ and $P=0.653$, respectively). There was no significant association in the subgroup analysis of BMI. Kellgren-Lawrence $(\mathrm{KL})$ grade 2 accounted for $44.4 \%$ of participants.

\section{Association between TNF- $\alpha$ rs1800629 polymorphism and OA risk}

The genotype distributions of TNF- $\alpha$ rs1800629 polymorphism are presented in Table 2. Genotype distributions

Table 1. Patient demographics and risk factors for osteoarthritis.

\begin{tabular}{lccc}
\hline Variable & Cases $(n=257)$ & Controls $(n=305)$ & $P$ \\
\hline Age (years) & $54.35 \pm 15.34$ & $54.59 \pm 15.40$ & 0.854 \\
Male/Female & $64 / 193$ & $71 / 234$ & 0.653 \\
Body mass index & $22.92 \pm 4.05$ & $22.34 \pm 3.95$ & 0.087 \\
Kellgren-Lawrence grade & & & \\
1 & $15(5.8 \%)$ & & \\
2 & $114(44.4 \%)$ & & \\
3 & $92(35.8 \%)$ & & \\
4 & $36(14.0 \%)$ & & \\
\hline
\end{tabular}

Data are reported as means \pm SD or number and percentage. Statistical analysis was done with the chi-squared test.

Table 2. Logistic regression analysis of associations between TNF- $\alpha$ rs 1800629 polymorphism and risk of osteoarthritis.

\begin{tabular}{|c|c|c|c|c|c|c|}
\hline \multirow[t]{2}{*}{ Genotype } & \multicolumn{2}{|c|}{ Cases $(n=257)$} & \multicolumn{2}{|c|}{ Controls $(n=305)$} & \multirow[t]{2}{*}{ OR $(95 \% \mathrm{Cl})$} & \multirow[t]{2}{*}{$\mathrm{P}$} \\
\hline & $\mathrm{n}$ & $\%$ & $\mathrm{n}$ & $\%$ & & \\
\hline GA vs GG & $96 / 120$ & $37.4 / 46.7$ & $140 / 142$ & $45.9 / 46.6$ & $0.81(0.57,1.16)$ & 0.250 \\
\hline $\mathrm{AA}$ vs GG & $33 / 120$ & $12.8 / 46.7$ & $19 / 142$ & $6.2 / 46.6$ & $2.06(1.11,3.80)$ & 0.022 \\
\hline $\mathrm{GA}+\mathrm{AA}$ vs $\mathrm{GG}$ & $129 / 120$ & $50.2 / 46.7$ & $159 / 142$ & $52.1 / 46.6$ & $0.96(0.69,1.34)$ & 0.812 \\
\hline $\mathrm{AA}$ vs $\mathrm{GA}+\mathrm{GG}$ & $33 / 216$ & $12.8 / 84.0$ & $19 / 282$ & $6.2 / 92.5$ & $2.27(1.26,4.10)$ & 0.007 \\
\hline$A$ vs $\mathrm{G}$ & $162 / 336$ & $31.5 / 65.4$ & $178 / 424$ & $29.2 / 69.5$ & $1.15(0.89,1.48)$ & 0.290 \\
\hline
\end{tabular}

Genotyping was successful in 249 cases and 301 controls. Bold data are statistically significant $(\mathrm{P}<0.05)$. 
of the controls in this study conformed to the HWE $(P=0.043)$. Logistic regression analyses revealed that the AA genotype of rs 1800629 polymorphism was associated with significantly increased risk of OA compared to the GG genotypes (AA vs GG: OR=2.06, 95\% $\mathrm{Cl}=1.11-3.80$, $\mathrm{P}=0.022$; Table 2).

\section{Meta-analysis results}

The characteristics of the studies exploring the associations between TNF- $\alpha$ rs 1800629 polymorphism and the risk of OA are listed in Table 3. Four Asian studies (including this study) and 7 Caucasian studies were identified in this meta-analysis. The Newcastle-Ottawa Scales (NOS)

Table 3. Characteristics of included studies for different genotypes.

\begin{tabular}{|c|c|c|c|c|c|c|c|c|c|c|c|}
\hline \multirow[t]{2}{*}{ Author, year } & \multirow[t]{2}{*}{ SOC } & \multirow[t]{2}{*}{ Ethnicity } & \multirow[t]{2}{*}{ Type of OA } & \multicolumn{2}{|c|}{ GG } & \multicolumn{2}{|c|}{ GA } & \multicolumn{2}{|c|}{ AA } & \multirow[t]{2}{*}{ HWE } & \multirow[t]{2}{*}{ NOS } \\
\hline & & & & case & control & case & control & case & control & & \\
\hline Moos, 2000 (13) & $\mathrm{HB}$ & Caucasian & Knee/Hip & 36 & 166 & 18 & 74 & 1 & 0 & 0.005 & 7 \\
\hline Romero, 2002 (17) & $\mathrm{HB}$ & Caucasian & Knee & 28 & 28 & 3 & 0 & 0 & 0 & $\mathrm{~N} / \mathrm{A}$ & 7 \\
\hline Sezgin, 2008 (11) & $\mathrm{HB}$ & Caucasian & Knee & 121 & 72 & 26 & 12 & 4 & 0 & 0.481 & 6 \\
\hline Han, 2012 (14) & PB & Asian & Knee & 79 & 258 & 188 & 33 & 34 & 0 & 0.305 & 6 \\
\hline Valle, $2012(18)$ & PB & Caucasian & Knee & 44 & 93 & 6 & 7 & 0 & 0 & 0.717 & 5 \\
\hline Ji, 2013 (19) & PB & Asian & Knee & 143 & 253 & 50 & 50 & 7 & 2 & 0.782 & 6 \\
\hline Cheng, 2013 (20) & PB & Asian & Knee & 143 & 253 & 50 & 49 & 7 & 3 & 0.716 & 7 \\
\hline Hamalainen, 2014 (15) & PB & Caucasian & Hand & 231 & 578 & 82 & 173 & 7 & 13 & 0.989 & 8 \\
\hline Abdel, 2017 (16) & PB & Caucasian & Knee & 180 & 115 & 25 & 82 & 5 & 13 & 0.749 & 7 \\
\hline This study & $\mathrm{HB}$ & Asian & Knee & 120 & 142 & 96 & 140 & 33 & 19 & 0.043 & 6 \\
\hline
\end{tabular}

SOC: source of controls; OA: osteoarthritis; PB: population-based controls; HB: hospital-based controls; NOS: Newcastle-Ottawa Scale; HWE: Hardy-Weinberg equilibrium.

Study

ID
$\%$

OR $(95 \% \mathrm{CI})$

Weight

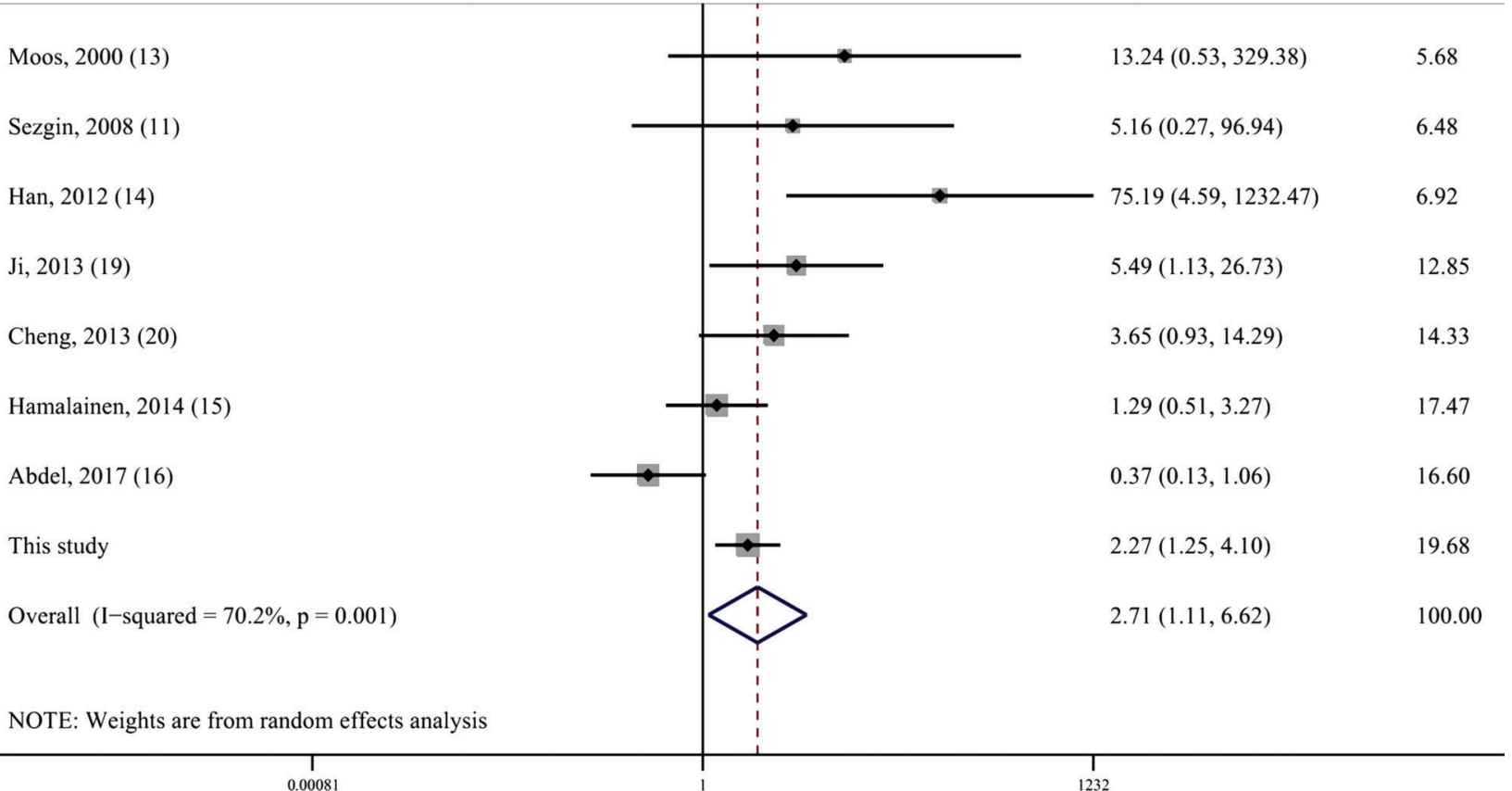

Figure 1. Forest plot showing odds ratio for the associations between rs1800629 polymorphism and osteoarthritis risk (AA vs GA + GG). 


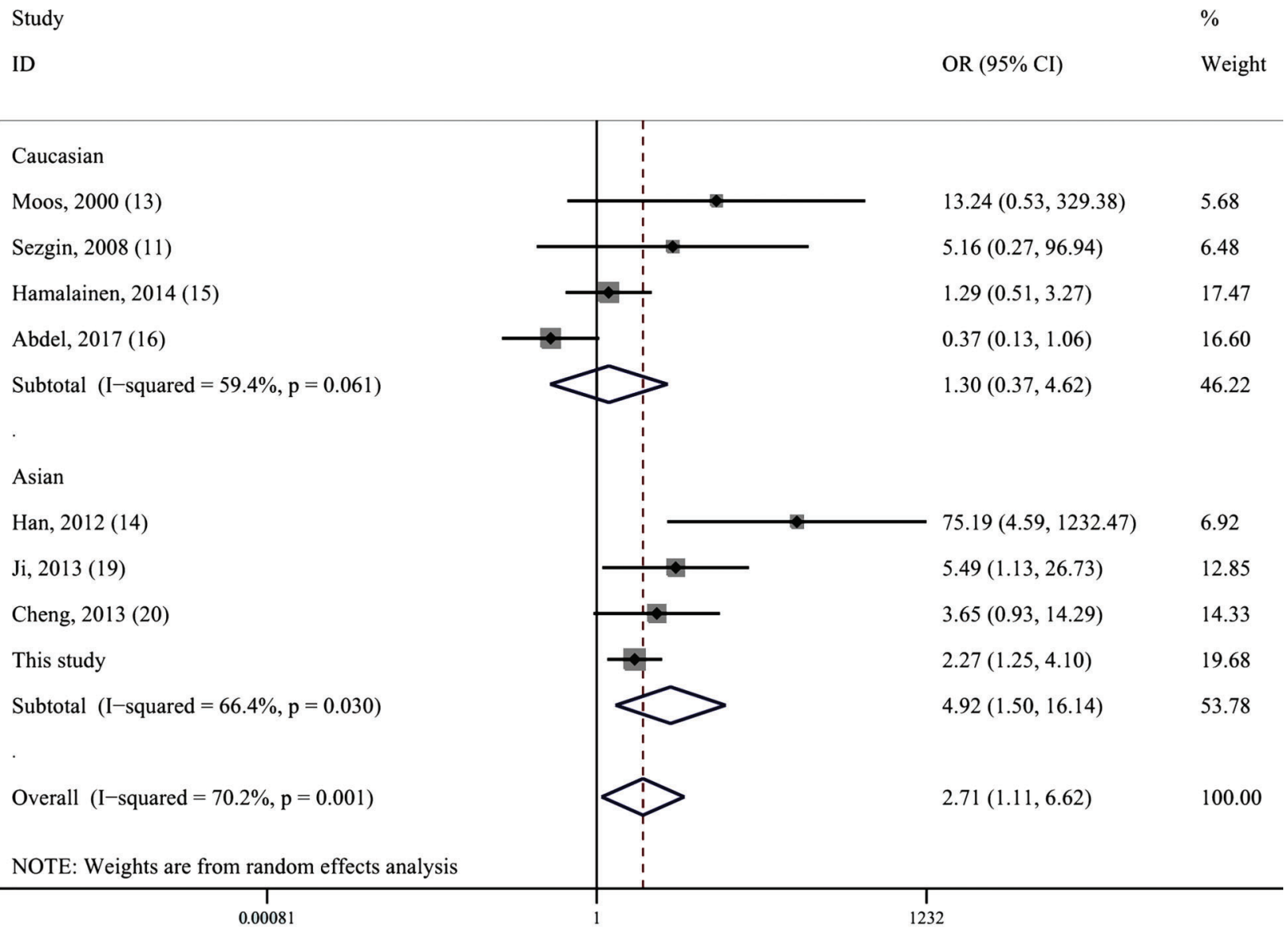

Figure 2. Stratification analyses of ethnicity between rs 1800629 polymorphism and osteoarthritis risk (AA vs GA+GG).

scores ranged from 6 to 8 stars, suggesting that studies were of high methodological quality.

Our meta-analysis revealed that TNF- $\alpha$ rs 1800629 polymorphism was associated with the increased risk of OA under recessive and homozygous models (AA vs GA+ GG: OR=2.71, 95\%Cl=1.11-6.62, $\mathrm{P}=0.029$; Figure 1). In the ethnicity subgroup analysis, we found that this SNP showed correlation with increased risk among Asian populations (AA vs $\mathrm{GA}+\mathrm{GG}$ : $\mathrm{OR}=4.92,95 \% \mathrm{Cl}=1.50-16.14$, $\mathrm{P}=0.009$; Figure 2), but not in Caucasian populations (Table 4).

\section{Discussion}

TNF- $\alpha$ stimulated chondrocyte responses that promote catabolism of type II collagen and proteoglycans, thereby compromising cartilage extracellular matrix integrity and tissue homeostasis in OA (22). TNF- $\alpha$ could increase the expression of cytokines and chemokines (MMP-1, MMP-3, MMP-13, and ADAMTS-4) in synovial cells and renew inflammatory mediators $(23,24)$. Some studies demonstrated that TNF- $\alpha$ induced chondrocyte death and hampered the migration of chondrogenic progenitor cells (25-27). In addition, studies revealed that TNF- $\alpha$ rs1800629 polymorphism was associated with high expression of TNF- $\alpha$ in knee OA (12). In this case-control study, we found that this SNP increased the risk of OA in a Chinese population. We also validated this significant association in the overall populations by a meta-analysis. Subgroup analysis of ethnicity indicated that this SNP increased the risk of OA among Asians, but not among Caucasians.

The relationship between TNF- $\alpha$ rs1800629 polymorphism and $\mathrm{OA}$ risk have been discussed previously (11-20). However, the results of these studies were contradictory. In 2000, Moos et al. (13) failed to find the association between TNF- $\alpha$ rs 1800629 polymorphism and OA susceptibility among Caucasians. The finding was also observed in the subsequent studies of Caucasian populations $(11,15,17,18)$. However, a recent study from Egypt obtained an association between rs1800629 polymorphism and knee OA (16). Subsequent studies $(14,19,20)$ from Asia also found that this SNP was associated with increased risk of OA. Munoz-Valle et al. (12) found that $\mathrm{G}$ allele of TNF- $\alpha$ rs 1800629 polymorphism was associated 
Table 4. Meta-analysis of association between TNF- $\alpha$ rs 1800629 polymorphism and the risk of osteoarthritis.

\begin{tabular}{|c|c|c|c|c|}
\hline Comparison & Studies & OR $(95 \% \mathrm{Cl})$ & P-value & P for heterogeneity \\
\hline \multicolumn{5}{|l|}{$A$ vs $G$} \\
\hline Caucasian & 7 & $1.14(0.59,2.20)$ & 0.707 & $<0.001$ \\
\hline Asian & 4 & $2.69(0.97,7.47)$ & 0.058 & $<0.001$ \\
\hline Total & 11 & $1.65(0.90,3.05)$ & 0.107 & $<0.001$ \\
\hline \multicolumn{5}{|c|}{$A A+G A$ vs $G G$} \\
\hline Caucasian & 7 & $1.10(0.52,2.31)$ & 0.802 & $<0.001$ \\
\hline Asian & 4 & $2.97(0.80,11.11)$ & 0.105 & $<0.001$ \\
\hline Total & 11 & $1.69(0.81,3.54)$ & 0.165 & $<0.001$ \\
\hline \multicolumn{5}{|c|}{$A A$ vs $G A+G G$} \\
\hline Caucasian & 4 & $1.30(0.37,4.62)$ & 0.685 & 0.061 \\
\hline Asian & 4 & $4.92(1.50,16.14)$ & 0.009 & 0.030 \\
\hline Total & 8 & $2.71(1.11,6.62)$ & 0.029 & 0.001 \\
\hline \multicolumn{5}{|l|}{$\mathrm{AA}$ vs $\mathrm{GG}$} \\
\hline Caucasian & 4 & $1.33(0.29,6.15)$ & 0.718 & 0.014 \\
\hline Asian & 4 & $7.05(1.43,34.68)$ & 0.016 & 0.001 \\
\hline Total & 8 & $3.20(1.08,9.55)$ & 0.037 & $<0.001$ \\
\hline \multicolumn{5}{|l|}{ GA vs GG } \\
\hline Caucasian & 7 & $1.05(0.51,2.18)$ & 0.886 & $<0.001$ \\
\hline Asian & 4 & $2.63(0.70,9.90)$ & 0.154 & $<0.001$ \\
\hline Total & 11 & $1.57(0.76,3.25)$ & 0.224 & $<0.001$ \\
\hline
\end{tabular}

with high mRNA and soluble expression in knee OA patients. However, the TNF- $\alpha$ rs1800629 genotypes did not show statistical difference between cases and controls. In addition, the sample size of the study by MunozValle et al. (12) was very small. Thus, we could not exclude the possibility that their findings might be falsepositive. We hypothesized that rs1800629 polymorphism may be in linkage disequilibrium with other potentially functional variants in TNF- $\alpha$ gene or closely linked susceptibility genes, which may contribute to the contradictory findings. In this study, our data showed that AA genotype was associated with the risk of OA. We do not know whether AA genotype is associated with higher production of TNF- $\alpha$ expression in this study, which warrants further study to validate the results. Small sample size, low statistical power, and/or clinical heterogeneity may account for the disparities of the above studies. In order to overcome the limitations of individual studies and resolve inconsistencies, Kou and Wu (28) reviewed 7 studies with 983 cases and 1355 controls and conducted a metaanalysis to derive a more precise estimation of the effect of TNF- $\alpha$ rs 1800629 polymorphism on OA risk in 2014. Their results revealed that this polymorphism increased the risk of $\mathrm{OA}$ in the allelic and recessive models (28). Ethnic subgroup analysis indicated that rs1800629 polymorphism was associated with the risk of OA among Asian populations (28). To date, there are 4 studies (3 Caucasian studies and this study) with moderate sample sizes $(12,15,16)$.
We re-evaluated the role of TNF- $\alpha$ rs1800629 polymorphism in the risk of $\mathrm{OA}$ by a meta-analysis. Our conclusion is almost in line with the conclusion of the meta-analysis of $\mathrm{Kou}$ and $\mathrm{Wu}(28)$ who reported that A allele or AA genotype of this SNP increased the risk of OA. However, we only observed that AA genotype was associated with increased risk of OA, but not $A$ allele. We believe our meta-analysis was more robust than the previous meta-analysis (28) due to larger sample size. Stratification analysis of ethnicity in this meta-analysis suggested that this SNP increased the risk of OA among Asians, but not among Caucasians. Several possible explanations for different findings of this SNP between Asians and Caucasians may account for these contradictory findings. First, genetic heterogeneity for OA may exist among different populations. Second, the discrepancy may be explained by clinical heterogeneity between the different ethnicities. Third, the sample sizes, different genotyping methods, and random errors may also be potential reasons for these disagreements. Further studies with larger sample sizes among other races are needed to verify these findings.

Some limitations of this study should be taken into consideration. One, confounding factors may have affected the results, such as smoking habit and weight. Two, the sample size of this study was not large, which might make our work underpowered. Three, lack of available original data prevented adjustment for other covariates such as age, gender, and lifestyle. Four, high heterogeneity was 
observed in this meta-analysis. Five, included studies mainly involved Asians and Caucasians and results may not be applied to other racial groups. Six, we did not evaluate whether AA genotype is associated with higher production of TNF- $\alpha$ expression in this study. Seven, only one SNP was investigated in this case-control study. Finally, there was no AA mutant genotype in some studies of this meta-analysis. In summary, TNF- $\alpha$ rs 1800629 polymorphism may be associated with increased risk of OA. The meta-analysis

\section{References}

1. Woolf $A D$, Pfleger B. Burden of major musculoskeletal conditions. Bull World Health Organ 2003; 81: 646-656.

2. Pereira D, Ramos E, Branco J. Osteoarthritis. Acta Med Port 2015; 28: 99-106, doi: 10.20344/amp.5477.

3. Johnson VL, Hunter DJ. The epidemiology of osteoarthritis. Best Pract Res Clin Rheumatol 2014; 28: 5-15, doi: 10.1016/ j.berh.2014.01.004.

4. Hirsch R, Lethbridge-Cejku M, Hanson R, Scott WW Jr., Reichle R, Plato CC, et al. Familial aggregation of osteoarthritis: data from the Baltimore Longitudinal Study on Aging. Arthritis Rheum 1998; 41: 1227-1232, doi: 10.1002/ 1529-0131(199807)41:7<1227::AID-ART13 > 3.0.CO;2-N.

5. MacGregor AJ, Spector TD. Twins and the genetic architecture of osteoarthritis. Rheumatology (Oxford) 1999; 38: 583-588, doi: 10.1093/rheumatology/38.7.583.

6. MacGregor AJ, Li Q, Spector TD, Williams FM. The genetic influence on radiographic osteoarthritis is site specific at the hand, hip and knee. Rheumatology (Oxford) 2009; 48: 277280, doi: 10.1093/rheumatology/ken475.

7. El-Tahan RR, Ghoneim AM, El-Mashad N. TNF-alpha gene polymorphisms and expression. Springerplus 2016; 5: 1508, doi: 10.1186/s40064-016-3197-y.

8. Chen C, Xie J, Rajappa R, Deng L, Fredberg J, Yang L. Interleukin-1beta and tumor necrosis factor-alpha increase stiffness and impair contractile function of articular chondrocytes. Acta Biochim Biophys Sin (Shanghai) 2015; 47: 121- 129, doi: 10.1093/abbs/gmu116.

9. Stannus O, Jones G, Cicuttini F, Parameswaran V, Quinn S, Burgess $\mathrm{J}$, et al. Circulating levels of IL-6 and TNF-alpha are associated with knee radiographic osteoarthritis and knee cartilage loss in older adults. Osteoarthritis Cartilage 2010; 18: 1441-1447, doi: 10.1016/j.joca.2010.08.016.

10. Kunisch E, Kinne RW, Alsalameh RJ, Alsalameh S. Proinflammatory IL-1beta and/or TNF-alpha up-regulate matrix metalloproteases-1 and -3 mRNA in chondrocyte subpopulations potentially pathogenic in osteoarthritis: in situ hybridization studies on a single cell level. Int J Rheum Dis 2016; 19: 557-566, doi: 10.1111/1756-185X.12431.

11. Sezgin M, Barlas IO, Ankarali HC, Altintas ZM, Turkmen E, Gokdogan T, et al. Tumour necrosis factor alpha -308G/A gene polymorphism: lack of association with knee osteoarthritis in a Turkish population. Clin Exp Rheumatol 2008; 26: 763-768.

12. Munoz-Valle JF, Oregon-Romero $E$, Rangel-Villalobos $H$, Martinez-Bonilla GE, Castaneda-Saucedo E, Salgado-Goytia $\mathrm{L}$, et al. High expression of TNF alpha is associated with -308 and -238 TNF alpha polymorphisms in knee osteoarthritis, Clin Exp Med 2014; 14: 61-67, doi: 10.1007/s10238-012-0216-3. also revealed an association between this SNP and OA risk. More studies with larger sample sizes are warranted to confirm this relationship.

\section{Acknowledgments}

This work was supported by the Administration of Traditional Chinese Medicine of Zhejiang province (20122A045)

13. Moos V, Rudwaleit M, Herzog V, Hohlig K, Sieper J, Muller B. Association of genotypes affecting the expression of interleukin-1beta or interleukin-1 receptor antagonist with osteoarthritis. Arthritis Rheum 2000; 43: 2417-2422, doi: 10.1002/1529-0131(200011)43:11 < 2417::AID-ANR7>3.0. CO;2-R.

14. Han L, Song JH, Yoon JH, Park YG, Lee SW, Choi YJ, et al. TNF-alpha and TNF-beta polymorphisms are associated with susceptibility to osteoarthritis in a Korean population. Korean J Pathol 2012; 6: 30-37, doi: 10.4132/KoreanJ Pathol.2012.46.1.30.

15. Hamalainen $S$, Solovieva $S$, Vehmas $T$, Leino-Arjas $P$, Hirvonen A. Variations in the TNFalpha gene and their interactions with the IL4R and IL10 genes in relation to hand osteoarthritis. BMC Musculoskelet Disord 2014; 15: 311, doi: 10.1186/1471-2474-15-311.

16. Abdel Galil SM, Ezzeldin N, Fawzy F, El-Boshy M. The single-nucleotide polymorphism (SNP) of tumor necrosis factor alpha $-308 \mathrm{G} / \mathrm{A}$ gene is associated with early-onset primary knee osteoarthritis in an Egyptian female population. Clin Rheumatol 2017; 36: 2525-2530, doi: 10.1007/ s10067-017-3727-1.

17. Oregon-Romero E, Munoz-Valle JF, Martin-Marquez BT. -308 tumor necrosis factor-alpha promoter polymorphism in patients with rheumatoid arthritis and osteoarthritis in the west of Mexico: preliminary results. Rev Vaccimonitor (Vacunologiay Temasafines) 2002; 11: 52-58.

18. Valle $A M$, Shang $Q$, Lu FH. The association between tumor necrosis factor-alpha -308G/A gene polymorphism and the risk of OA. Chin Clini Rehab 2012; 65: 66-68.

19. Ji B, Shi J, Cheng X, Zhou J, Zhou Q, Cao C, et al. Association analysis of two candidate polymorphisms in the tumour necrosis factor-alpha gene with osteoarthritis in a Chinese population. Intl Orthop 2013; 37: 2061-2063, doi: 10.1007/s00264-013-1931-4.

20. Cheng $\mathrm{X}, \mathrm{Cao} \mathrm{C}, \mathrm{Ji} \mathrm{B}$. Association of tumor necrosis factoralpha-308 polymorphism with osteoarthritis in a Chinese population. Chinese Journal of Orthopaedic Trauma 2013; 15: 607-609.

21. Kellgren JH, Lawrence JS. Radiological assessment of osteoarthrosis, Ann Rheum Dis 1957; 16: 494-502, doi: 10.1136/ ard.16.4.494.

22. Goldring MB, Goldring SR. Osteoarthritis. J Cel Physiol 2007; 213: 626-634, doi: 10.1002/jcp.21258.

23. Lee SW, Song YS, Lee SY, Yoon YG, Lee SH, Park BS, et al. Downregulation of protein kinase CK2 activity facilitates tumor necrosis factor-alpha-mediated chondrocyte 
death through apoptosis and autophagy. PloS One 2011; 6: e19163, doi: 10.1371/journal.pone.0019163.

24. Xue J, Wang J, Liu Q, Luo A. Tumor necrosis factor-alpha induces ADAMTS-4 expression in human osteoarthritis chondrocytes. Mol Med Rep 2013; 8: 1755-1760, doi: 10.3892/mmr.2013.1729.

25. Lopez-Armada MJ, Carames B, Lires-Dean M, Cillero-Pastor B, Ruiz-Romero C, Galdo F, et al. Cytokines, tumor necrosis factor-alpha and interleukin-1beta, differentially regulate apoptosis in osteoarthritis cultured human chondrocytes, Osteoarthritis Cartilage 2006; 14: 660-669, doi: 10.1016/j.joca.2006. 01.005 .
26. Joos $H$, Wildner A, Hogrefe $C$, Reichel $H$, Brenner RE. Interleukin-1 beta and tumor necrosis factor alpha inhibit migration activity of chondrogenic progenitor cells from nonfibrillated osteoarthritic cartilage, Arthritis Res Ther 2013; 15: R119, doi: 10.1186/ar4299.

27. Ye Z, Chen $\mathrm{Y}$, Zhang $\mathrm{R}$, Dai $\mathrm{H}$, Zeng $\mathrm{C}$, Zeng $\mathrm{H}$, et al. c-Jun N-terminal kinase - C-Jun pathway transactivates Bim to promote osteoarthritis. Can J Physiol Pharmacol 2014; 92: 132-139, doi: 10.1139/cjpp-2013-0228.

28. Kou S, Wu Y. Meta-analysis of tumor necrosis factor alpha -308 polymorphism and knee osteoarthritis risk. BMC Musculoskelet Disord 2014; 15: 373., doi: 10.1186/1471-2474-15-373. 